\title{
In vitro Performance of Cobas 4800 HPV Test in Females of Lodz Region, Poland
}

\author{
Beata Smolarz ${ }^{1 *}$, Jan Bieńkiewicz², Bartosz Kulig ${ }^{3}$, Krzysztof Szyłło ${ }^{3}$ and Hanna Romanowicz ${ }^{1}$ \\ ${ }^{1}$ Laboratory of Cancer Genetics, Department of Pathology, Institute of Polish Mother's Memorial Hospital, Poland \\ ${ }^{2}$ Department of Surgical, Endoscopic and Oncologic Gynaecology, Institute of Polish Mother's Memorial Hospital, Poland \\ ${ }^{3}$ Department of Operative Gynaecology, Polish Mother's Memorial Hospital - Research Institute, Poland
}

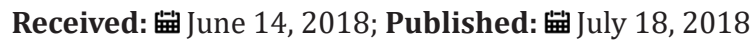

*Corresponding author: Beata Smolarz, Laboratory of Cancer Genetics, Department of Pathology, Institute of Polish Mother's Memorial Hospital, Rzgowska 281/289, 93-338 Lodz, Poland, Tel: +48-42 27112 90; Email: smolbea@wp.pl

\begin{abstract}
Background: Although screening algorithm has introduced an efficient tool to tackle cervical cancer, both morbidity and mortality in this disease are still a major concern in medicine. It has been already proven that Human papillomavirus (HPV) infection promotes the development of precancerous lesions and eventually leads to cervical cancer. This study aimed at analysis of the prevalence of high risk HPV DNA (HR HPV) in females of Lodz region, central Poland.
\end{abstract}

Methods: In this study we employed Cobas 4800 HPV test to detect the HR HPV in 240 cervical smear samples.

Results: 48 patients (20\%) proved to be positive regarding HPV-16 DNA and 32 patients (13\%)-regarding HPV-18 DNA. In overall assessment, in 80 patients (33\%) we have detected oncogenic HPV subtypes, other than the two abovementioned.

Conclusion: Cobas 4800 HPV test is a viable, effective, easy and quick tool in detecting high risk HPV DNA.

Keywords: HPV; Cervical Cancer; Genotyping

\section{Background}

Cervical cancer is one of the most common malignancies in women worldwide. In Poland is it the sixth most frequent malignancy in females and third just in female genitals. Due to well-developed screening strategies that enable early detection of precancerous lesions and cancer itself, both morbidity and mortality are steadily decreasing. However, some women evade the screening algorithm and thus still in a substantial percentage of cases patient learn of the diagnosis at rather advanced stage of the disease [1,2]. One of the milestones in clinical medicine was the discovery of the effect the long-lasting exposition to Human papillomavirus (HPV) infection exerts on development of cervical cancer and its precancerous stage-cervical intraepithelial neoplasia: CIN [3-5]. One even claims, that HPV infection may be present in more than $99 \%$ of cervical cancer cases. HPV belongs to Papovaviridae virus family, which consists of Papillomavirus and Polyomavirus [5-6]. The family are DNA viruses containing double-stranded DNA, are icosahedral in shape, and do not possess a lipoprotein envelope. HPV, which genome consists of approx. 8000 nucleotides, divides in more than 118 various types, 40 of which may infect the mucosa of ano-genital region in humans [8-9]. However, only certain types are considered to be of high risk potential regarding cervical cancer and its precancerous stage [10-15].
International Agency of Research on Cancer concluded in its multicenter study that the odds ratio for planoepithelial cervical cancer in HPV-infected individuals was almost 160 (ranging from 109 to 276 in different research centers of the study worldwide), however the analysis of carriers was limited only to certain approved HPV detection kits [16]. Yet, it has to be emphasized, that although durable exposition to HR HPV is a crucial element in the etiopathogenesis of cervical cancer and CIN, only a small share of infected individuals develop the abovementioned conditions. Despite that sex-transmitted HPV infection is extremely frequent (up to $75 \%$ in exposed women), more that $90 \%$ of females establish proper immunological response to eventually combat the virus within 6-24 months of infection resulting in no medical aftereffects whatsoever [17-22]. Furthermore, contagion of any of HPV types may result in CIN, but the above-mentioned immunological mechanisms reduces the risk down to a minimum in most cases [23]. Unfortunately, HPV is extremely difficult to culture in vitro and not every infected individual promotes an immunological response with antibodies to be easily identified. Thus, PCR analysis of HPV DNA is a useful tool in detection of infection that overcomes the before-mentioned obstacles. In this paper we have engaged PCR (Cobas 4800 HPV test) to detect HR HPV DNA in high-risk females in Lodz region, central Poland. 


\section{Materials and Methods \\ HPV DNA Detection}

Cervical canal swabs (Cobas PCR collection media, Roche Molecular Systems, Inc.) were obtained in 240 patients. The patients' age ranged from 25 to 50 (mean: 34, SD: 6,7). Cobas 4800 HPV test (Roche Diagnostics, GmbH, Mannheim, Germany) -which is a qualitative test device for detection HPV DNA-was used to analyze the samples. This test amplifies target DNA in cervical epithelium cells (Cobas PCR collection media, Roche Molecular Systems, Inc.) by PCR and nucleic acids hybridization to detect 14 HR HPV types of which HPV-16 and -18 are of greatest importance. Moreover, this analysis also enables detection of other HR HPV types $(31,33,35$, $39,45,51,52,56,58,59,66,68)$ in clinically significant levels of infectivity.

\section{Sample Preparation}

Sample preparation was a fully automatized process performed by Cobas 4800 HPV test device (Roche Diagnostics GmbH, Mannheim, Germany). After collection to the culture medium according to manufacturer's manual (Cobas PCR collection media) the samples were digested under denaturing conditions in elevated temperatures and then lysed with chaotropic agent. Liberated nucleic acids with beta-globin DNA-acting as process control-were cleavaged by absorption to magnetic glass molecules.

\section{PCR Amplification}

Cobas 4800 HPV test primers were used do amplify DNA of 14 HR HPV types $(16,18,31,33,35,39,45,51,52,56,58,59,66,68)$. Fluorescent oligonucleotide probes match with polymorphic region of primer-determined sequence. Human beta-globulin-oriented fluorescent probe provided quality control of whole reaction.

\section{Results}

Table 1 demonstrates the frequency of HR HPV in the patients. The test revealed 48 samples (20\%) to be positive regarding HPV16 and 32 samples (13\%) contained HPV-18. Moreover, 80 patients (33) were positive regarding oncogenic HR HPV other than HPV-16 and -18. In 80 patients no HR HPV was detected.

a) Statistical Analysis: Statistical evaluation was carried out using the chi 2 and Fisher test.

Table 1: Prevalence of HR HPV in females in Lodz region, Central Poland.

\begin{tabular}{|c|c|c|c|c|c|c|c|}
\hline \multicolumn{7}{|c|}{ Patients (n=240) } \\
\hline \multicolumn{2}{|c|}{ HPV-16 } & \multicolumn{2}{|c|}{ HPV-18 } & \multicolumn{2}{c|}{$\begin{array}{c}\text { HR HPV other } \\
\text { than HPV-16 and } \\
\text { HPV-18 }\end{array}$} & $\begin{array}{c}\text { No HR HPV DNA } \\
\text { detected }\end{array}$ \\
\hline $\mathrm{n}$ & $\%$ & $\mathrm{n}$ & $\%$ & $\mathrm{n}$ & $\%$ & $\mathrm{n}$ & $\%$ \\
\hline 48 & 20.00 & 32 & 13.33 & 80 & 33.33 & 80 & 33.33 \\
\hline
\end{tabular}

\section{Discussion}

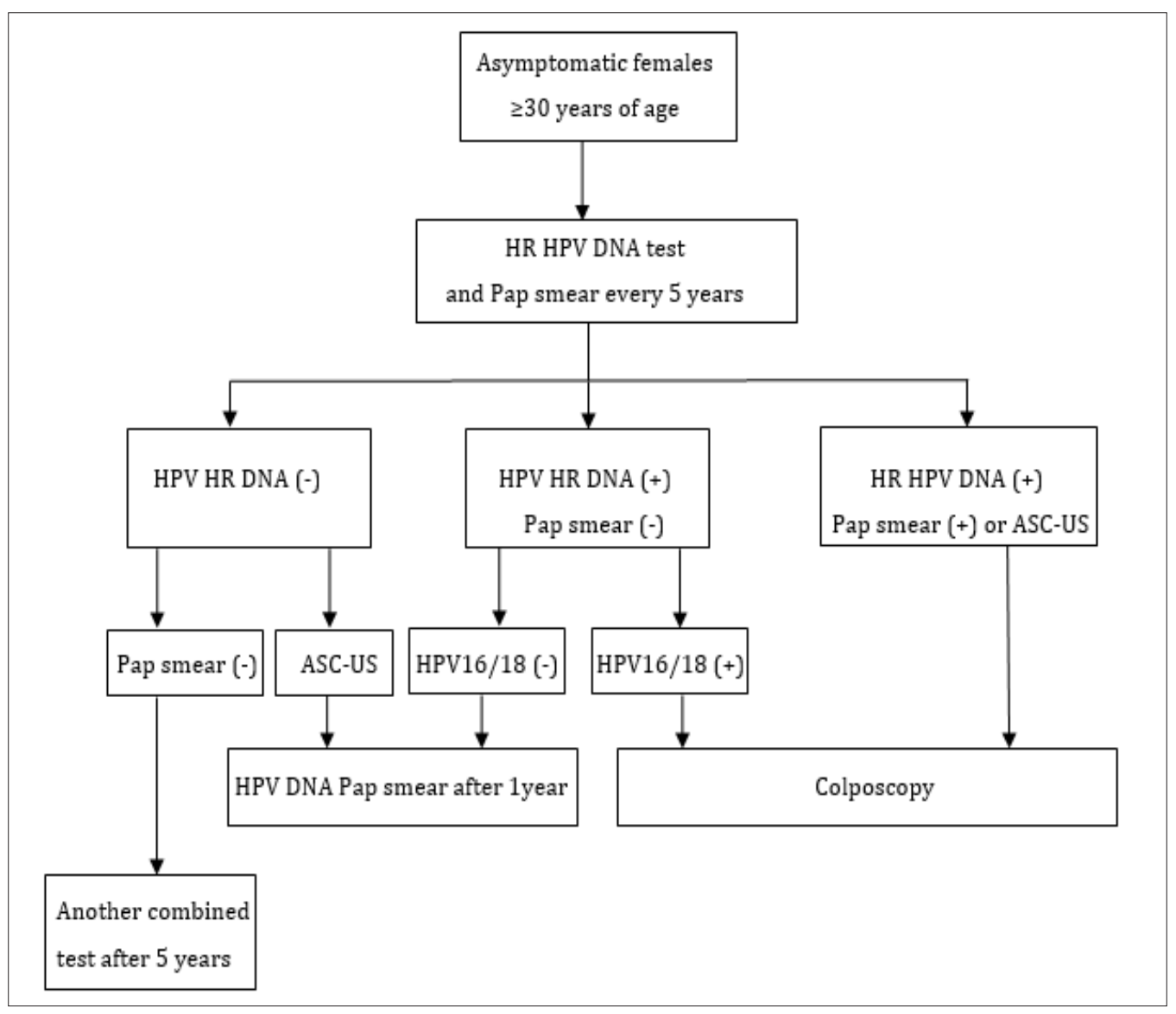

Figure 1: Guidelines on application of HPV DNA test in prophylactics of cervical cancer. 
Both detection of early lesions and identification of predisposing factors have equally crucial importance in prophylactics of cervical cancer. Recognition of females infected with HR HPV may result in building a special high-risk group that is subject to more detailed clinical scrutiny than the general population Up until now, efforts on estimating the prevalence of subclinical HPV infection among females have produced incoherent results that varied with regard to analyzed population and employed methodology. Unfortunately, HPV cannot be simply cultured in human cells in vitro and there is no animal model that could be useful, which literally makes the virus antigen impossible to identify with typical serologic laboratory tactics. Thus, HPV detection became accessible on a larger scale only with the advent of molecular biology tools. It is now clear that PCR is the most sensitive means in such analysis and enables detection of one copy of the virus in as many as 105106 cells which made it a routinely employed part of modern laboratories worldwide. Moreover, it has been proven that data obtained by PCR is coherent, repeatable and specific. Literature also provides support for clinical application of HPV DNA testing: there is a higher detection of high risk lesions in NILM patients (Negative for Intraepithelial Lesion or Malignancy) and lower rate of unnecessary colposcopy and treatment in females over 21 years of age with ASC-US [24-28]. Moreover, HPV DNA testing is more sensitive than standard cervical smears in detection advanced lesions in population group. Furthermore, some population-based screening programs have already introduced HPV DNA testing as primary test. Figure 1 demonstrates the guidelines of Polish Gynecologic Association Experts Group and The National Chamber of Laboratory Diagnosticians on application of HPV DNA test in prophylactics of cervical cancer.

\section{Conclusion}

Laboratory of Cancer Genetics, Department of Pathology, Polish Mother's Memorial Hospital-Research Institute, Lodz, Poland has introduced the described above methodology (Cobas 4800 HPV test) into routine application in detecting HR HPV infections. The abovementioned results prove it is a viable, effective, easy and quick tool in detecting high risk HPV DNA and can be introduced into primary screening.

\section{Declarations}

\section{Ethics Approval and Consent to Participate}

This work was supported by the Institute of Polish Mother's Memorial Hospital, Lodz, Poland from the Statutory Development Fund. All procedures performed in studies involving human participants were in accordance with the ethical standards of the institutional and/or national research committee and with the 1964 Helsinki declaration and its later amendments or comparable ethical standards. All the study participants gave a written informed consent.

\section{Consent for Publication}

Not applicable, the manuscript doesn't contain any individual person's data.

\section{Availability of Data and Material}

Data will not be shared, because it is part of a clinical database.

\section{Competing Interests}

Authors declare no conflict of interest. Author Beata Smolarz declares that she has no conflict of interest. Author Jan Bieńkiewicz declares that he has no conflict of interest. Author Bartosz Kulig declares that he has no conflict of interest. Author Krzysztof Szyłło declares that he has no conflict of interest. Author Hanna Romanowicz declares that she has no conflict of interest.

\section{Acknowledgement}

Authors acknowledge the financial support provided by the Institute of Polish Mother's Memorial Hospital, Lodz, Poland, to conduct the study.

\section{References}

1. Kozakiewicz B (2003) Nowotwory złośliwe narządu rodnego, Nowa Medycyna 122: 111-127.

2. Żołciak-Siwińska A, Jońska-Gmyrek J, Socha J (2012) Recurrent cervical cancer-therapeutic options. Ginekol Pol 83(7): 527-531.

3. Burd EM (2003) Human Papillomavirus and cervical cancer. Clin Microbiol Rev 16(1): 1-17.

4. Zur Hausen H (2002) Papillomaviruses and cancer: from basic studies to clinical application. Nat Rev Cancer 2(5): 342-350.

5. Walboomers JM, Jacobs MV, Manos MM, Bosch FX, Kummer JA, et al. (1999) Human Papillomavirus is a necessary cause of invasive cervical cancer worldwide. J Pathol 189(1): 12-19.

6. Bernard HU (2005) The clinical importance of the nomenclature, evolution and taxonomy of human papillomaviruses. J Clin Virol 32 (Suppl.1): S1-6.

7. Molijn A, Kleter B, Quint W, Van Doorn LJ (2005) Molecular diagnosis of human papillomavirus (HPV) infections. J Clin Virol 32 (Suppl. 1): S4351.

8. Zur Hausen H (1996) Roots and perspectives of contemporary papillomavirus research. J Cancer Res Clin Oncol 122(1): 3-13.

9. De Villiers EM, Fauquet C, Broker TR, Bernard HU, Zur Hausen H (2004) Classification of papillomaviruses. Virology 324(1): 17-27.

10. Franco EL, Rohan TE, Villa LL (1999) Epidemiologic evidence and human papillomavirus infection as a necessary cause of cervical cancer. J Natl Cancer Inst 91(6): 506-511.

11. Lorincz AT, Reid R, Jenson AB, Greenberg MD, Lancaster W, et al. (1992) Human papillomavirus infection of the cervix: relative risk associations of 15 common anogenital types. Obstet Gynecol 79(3): 328-337.

12. Bosch FX, Manos MM, Muñoz N, Sherman M, Jansen AM, et al. (1995) Prevalence of human papillomavirus in cervical cancer: a worldwide perspective. a worldwide perspective. International biological study on cervical cancer (IBSCC) Study Group. J Natl Cancer Inst 87(11): 796-802.

13. Bosch FX, Lorincz A, Muñoz N, Meijer CJ, Shah KV (2002) The causal relation between human papillomavirus and cervical cancer. J Clin Pathol 55(4): 244-265.

14. Munoz N, Bosch FX, de Sanjose S, Herrero R, Castellsague X, et al. (2003) International Agency for Research on Cancer Multicenter Cervical Cancer Study Group. Epidemiologic classification of Human Papillomavirus types associated with cervical cancer. N Engl J Med 348(6): 518-527.

15. Clifford GM, Smith JS, Plummer M, Muñoz N, Franceschi S (2003) Human papillomavirus types in invasive cervical cancer worldwide; a metaanalysis. Br J Cancer 88(1): 63-73.

16. Koutsky L (1997) Epidemiology of genital human papillomavirus infection. Am J Med 102(5A): 3-8.

17. Winer RL, Kiviat NB, Hughes JP, Adam DE, Lee SK, et al. (2005) Development and duration of human papillomavirus lesions, after initial infection. J Infect Dis 191(5): 731-8. 
18. Moscicki AB, Schiffman M, Kjaer S, Villa LL (2006) Chapter 5: Updating the natural history of HPV and anogenital cancer. Vaccine 24 (Suppl. 3) S3/42-51.

19. Moscicki AB, Ellenberg JH, Farhat S, Xu J (2004) Persistence of human papillomavirus infection in HIV-infected and -uninfected adolescent girls: risk factors and differences, by phylogenetic type. J Infect Dis 190(1): 37-45.

20. Palmer Castle PE, Schifman M, Herrero R (2005) A prospective study of age trends in cervical human papillomavirus acquisition and persistence in Guanacaste, Costa Rica. J Infect Dis 191(11): 1808-16.

21. Denise Zielinski G, Snijders PJ, Rozendaal L, Voorhorst FJ, Runsink AP, et al. (2001) High-risk HPV testing in women with borderline and mild dyskaryosis: long-term follow-up data and clinical relevance. J Pathol 195(3): 300-306.

22. Holowaty P, Miller AB, Rohan T, To T (1999) Natural history of dysplasia of the uterine cervix. J Natl Cancer Inst 91(1): 252-258.

23. Nobbenhuis MA, Helmerhorst TJ, van den Brule AJ, Rozendaal L, Voorhorst FJ, et al. (2001) Cytological regression and clearance of high risk human papillomavirus in women with an abnormal cervical smear Lancet 358(9295): 1782-1783.

24. Ronco G, Giorgi-Rossi P, Carozzi F, Confortini M, Dalla Palma P, et al. (2010) New Technologies for Cervical Cancer screening (NTCC) Working Group. Efficacy of human papillomavirus testing for the detection of invasive

\section{ISSN: 2574-1241}

DOI: $10.26717 / B J S T R .2018 .07 .001434$

Beata Smolarz. Biomed J Sci \& Tech Res

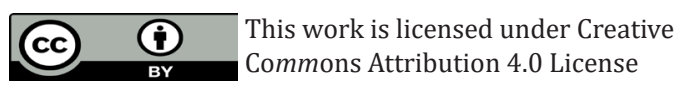

Submission Link: https://biomedres.us/submit-manuscript.php cervical cancers and cervical intraepithelial neoplasia: a randomized controlled trial. Lancet Oncol 11(3): 249-257.

25. Saslow D, Solomon D, Lawson HW, Killackey M, Kulasingam SL, (2012) American Cancer Society; American Society for Colposcopy and Cervical Pathology; American Society for Clinical Pathology. American Cancer Society, American Society for Colposcopy and Cervical Pathology, and American Society for Clinical Pathology Screening Guidelines for the Prevention and Early Detection of Cervical Cancer. Am J Clin Pathol 137(4): 516-542.

26. Stoler MH, Castle PE, Solomon D, Schiffman M (2007) American Society for Colposcopy and Cervical Pathology. The expanded use of HPV testing in gynecologic practice per ASCCP-guided management requires the use of well-validated assays. Am J Clin Pathol 127(3): 335-337.

27. Stoler MH, Wright TC Jr, Sharma A, Zhang G, Apple R, et al. (2012) ATHENA (Addressing THE Need for Advanced HPV Diagnostics) Study Group. The Interplay of age stratification and HPV testing on the predictive value of ASC-US cytology. Am J Clin Pathol 137(2): 295-303.

28. Józefiak A, Kędzia W, Kotarski J, Poręba R, Puacz E, et al. (2013) Guidelines for application of molecular tests identifying HR HPV DNA in the prevention of cervical cancer. Statement of experts from PGS (PTG) and NCLD (KIDL). Ginekol Pol 84(4): 395-399.

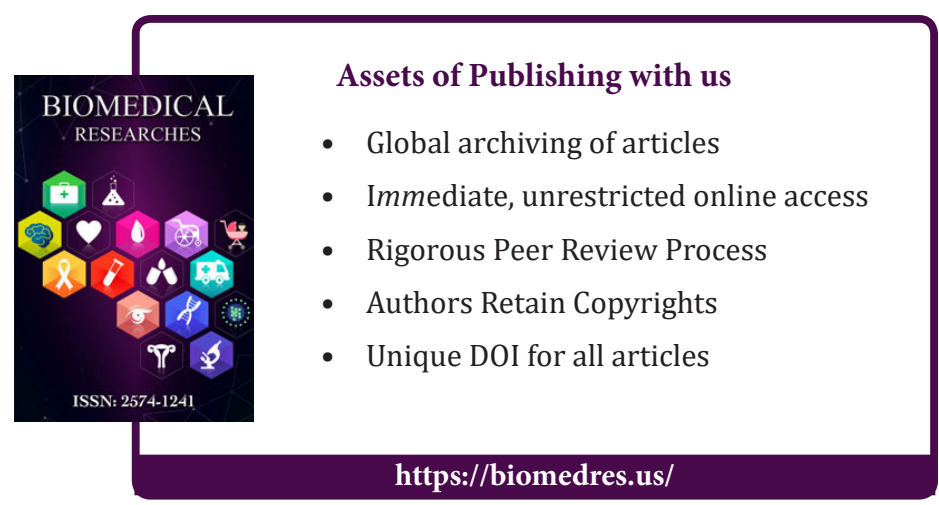

